\section{Influence of Preoperative Patient Factors on TKA Outcomes}

\author{
Tomas Sveikata, Paulius Kanopa*, Karolina Daunaraite, \\ Paulius Mankevicius, Vytautas Tutkus, Giedrius Petryla, \\ Jaunius Kurtinaitis, Sigitas Ryliskis, Narunas Porvaneckas, \\ Valentinas Uvarovas and Igoris Satkauskas
}

Faculty of Medicine, Vilnius University, Vilnius, Lithuania

\begin{abstract}
Background: Osteoarthritis $(O A)$ is one of the most disabling diseases in developed countries. In later stages of the disease, surgical treatment becomes the main alternative. Total Knee Arthroplasty (TKA) has proved a successful and cost-effective treatment for improving pain, function, mental health and overall quality of life in patients with severe knee arthritis. However up to $20 \%$ of patients are not satisfied with the outcome of the surgery. Being able to pre-operatively estimate which patient would have satisfactory results after the surgery is beneficial to guide further clinical decision. The aim of this study was to prospectively evaluate the influence of pre-operative patient factors on patient reported outcome after TKA.
\end{abstract}

Methods: 314 patients who underwent TKA in Vilnius University Hospital between end of 2012 and middle of 2014 year were included in a study. The influence of preoperative patient factors on the TKA outcome according to Western Ontario and McMaster Universities Osteoarthritis Index (WOMAC) change score was analyzed.

Results: The preoperative WOMAC pain score was the strongest determinant of the WOMAC pain change score one year after TKA. The preoperative WOMAC function and SF-12 mental health scores were the strongest determinants of the WOMAC function change score one year after TKA.

Conclusion: Lower preoperative knee pain, function scores and better mental health function results in greater change.

Keywords: Mental health; Osteoarthritis; Total knee arthroplasty; WOMAC

*Corresponding author: Paulius Kanopa, Faculty of Medicine, Vilnius University, M. K. Čiurlioniost. 21, Vilnius, Lithuania, Tel: +370 68792500; E-mail: paulius. kanopa@gmail.com

Citation: Sveikata T, Kanopa P, Daunaraite K, Mankevicius P, Tutkus V, et al. (2021) Influence of Preoperative Patient Factors on TKA Outcomes. J Gerontol Geriatr Med 7: 087.

Received: February 22, 2021; Accepted: March 05, 2021; Published: March 12, 2021

Copyright: (c) 2021 Sveikata T, et al. This is an open-access article distributed under the terms of the Creative Commons Attribution License, which permits unrestricted use, distribution, and reproduction in any medium, provided the original author and source are credited.

\section{Introduction}

Osteoarthritis (OA) is one of the most disabling diseases in developed countries [1]. In later stages of the disease, surgery becomes the main alternative [2,3]. Total Knee Replacement (TKR) has proved a successful and cost-effective treatment for improving pain and function in patients with arthritis [3]. However up to $20 \%$ of patients are not satisfied with the surgery [4]. Therefore a traditional indicator of surgical success such as implant survival, may not mirror the patient's postoperative experience, which these days assessed with Patient-Reported Outcome Measures (PROMs) [5]. Patient-Reported Outcome Measures (PROMs) have become a corner-stone of outcome assessment after joint surgery [5]. Numerous PROMs are used to measure the outcome. Western Ontario and McMaster Universities Arthritis Index (WOMAC) and the Short Form-12 (SF-12) are most commonly used. WOMAC is a joint specific instrument for measuring clinical outcome in patients treated for knee osteoarthritis [6]. Various patient-related factors can be associated with poor outcome after TKA, including, age, gender, obesity, education and social support [7-9]. It's important to identify those preoperative risk factors in order to understand why some people fail to benefit from TKA. The aim of this study was to evaluate patient factors and preoperative pain, function according to WOMAC and physical and mental function according to SF-12 that might influence the patient reported results after TKA.

\section{Methods}

The prospective observational study was performed at Vilnius University Hospital, Vilnius, Lithuania, from October 2012 to April 2014. The study protocol was approved by the Regional Ethical Committee of the Vilnius Regional Bioethics Committee, Vilnius, M.K. Ciurlionio 21/27, LT-03101, Lithuania. The cohort consisted of patients from Vilnius University Hospital, orthopedic department. Patients scheduled for primary TKA were screened for inclusion. All enrolled patients gave a written consent. Flowchart of study cohort is shown in Figure 1. Three hundred fourteen participants were enrolled and two hundred ninety four patients completed the study.

Preoperative patient's data was collected during their preoperative evaluation. Information included sex, age, education, social support, height and weight was measured (body mass index (BMI) was calculated), residence place, co-morbidities. We divided all patients in to two groups according to age (younger than 75 and older). Usually the elderly are lumped together, grouping everyone over the age of 65. But a 65-year-old's experience of life is much different from a 90-year-old's. In general older adult population is divided into three life-stage subgroups: the young-old (approximately 65-74), the middle-old (ages 75-84), and the old-old (over age 85) [10]. We took a cut-off between young-old and middle-old subgroups. BMI is a simple index that is commonly used to classify underweight, overweight and obesity. We used WHO's recommendation for splitting patients in groups according to BMI: I. $\mathrm{BMI}<30$ (patients with normal 
Citation: Sveikata T, Kanopa P, Daunaraite K, Mankevicius P, Tutkus V, et al. (2021) Influence of Preoperative Patient Factors on TKA Outcomes. J Gerontol Geriatr Med 7: 087.

weight and over-weight), II. BMI 30-34.9 (obese patients class I), III. BMI $\geq 35$ (obese patients class II and class III) [11]. Patient's educational level either low (secondary school or vocational training) or high (University). Patients lived in rural or urban territories. Social support was determined by living alone or with somebody. Patients underwent radiographic examination and were grouped according to Ahlback osteoarthritis stages [12]. According to walking ability patients were grouped to Charnley classes [13].
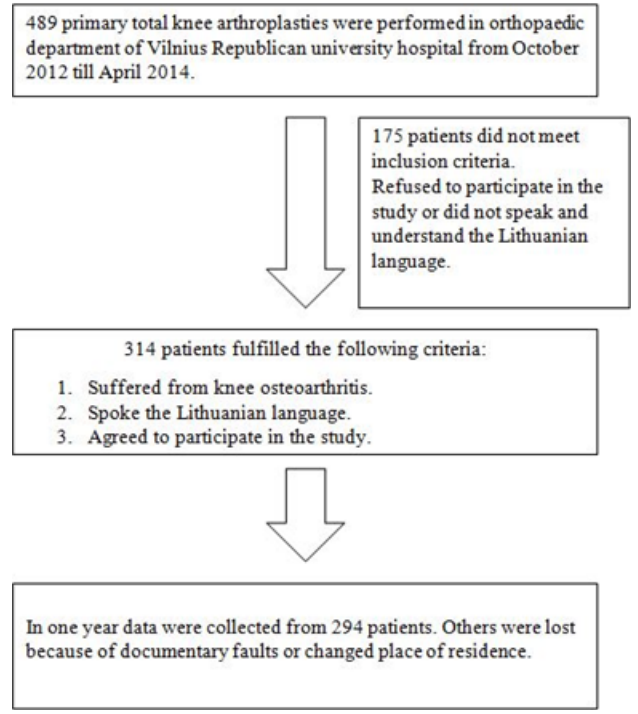

Figure 1: Flowchart of study cohort.

Patients filled up two validated and originally authorized Lithuanian translations of questionnaires: the WOMAC and SF-12; before and one year after TKA. The WOMAC is a disease-specific instrument with 3 dimensions: pain, joint stiffness and physical function. It consists of 24 items ( 5 for pain, 2 for stiffness and 17 for function) [6]. We transformed WOMAC scores to a 0 to100 point scale for each domain (with 100 being the best score).

The SF-12 score is a generic health measure of a patient's overall physical and mental wellbeing. Physical and Mental Health Composite Scores (PCS and MCS) are from 0 to 100, where zero indicates the lowest level of health and 100 the highest [14]. All TKA were made using cemented implants without resurfacing patella and all patients underwent similar rehabilitation program. Preoperative and in one year clinical outcome scores were analyzed as well as the change in score between preoperative and latest score.

\section{Statistical Analysis}

Influence of preoperative patient factors on knee pain and function after TKA were analysed. Multiple linear regression was used to estimate the influence of preoperative factors on the outcomes according to WOMAC change score. A p-value of $<0.05$ was considered to be statistically significant.

\section{Results}

Preoperative predictors of WOMAC pain and function score change in one year after TKA were calculated. The multiple linear regression models are presented in tables 1 and 2 .

\begin{tabular}{|c|c|c|c|}
\hline \multicolumn{4}{|c|}{ Change WOMAC pain } \\
\hline & Coef & $95 \%$ CI & p-value \\
\hline Age & -0.06 & $-0.21 ; 0.09$ & 0.466 \\
\hline \multicolumn{4}{|l|}{ Sex } \\
\hline Male & \multicolumn{3}{|l|}{ Ref. } \\
\hline Female & -1.35 & $-4.50 ; 1.80$ & 0.400 \\
\hline BMI & -0.04 & $-0.24 ; 0.16$ & 0.697 \\
\hline \multicolumn{4}{|l|}{ Social Support } \\
\hline No & \multicolumn{3}{|l|}{ Ref. } \\
\hline Yes & 0.46 & $-2.07 ; 2.99$ & 0.720 \\
\hline \multicolumn{4}{|l|}{ Level of Education } \\
\hline Higher & \multicolumn{3}{|l|}{ Ref. } \\
\hline Lower & -0.37 & $-2.80 ; 2.05$ & 0.762 \\
\hline \multicolumn{4}{|l|}{ Residence } \\
\hline Urban & \multicolumn{3}{|l|}{ Ref. } \\
\hline Rural & 0.96 & $-2.07 ; 3.99$ & 0.532 \\
\hline preop. WOMAC pain & -0.90 & $-0.97 ;-0.83$ & $<0.001$ \\
\hline \multicolumn{4}{|l|}{ Charnley Class } \\
\hline $\mathbf{A}$ & \multicolumn{3}{|l|}{ Ref. } \\
\hline B & -0.94 & $-3.73 ; 1.86$ & 0.511 \\
\hline C & -1.46 & $-5.34 ; 2.42$ & 0.459 \\
\hline \multicolumn{4}{|l|}{ AHLBACK } \\
\hline $1+2$ & \multicolumn{3}{|l|}{ Ref. } \\
\hline $3+4$ & 1.19 & $-1.09 ; 3.47$ & 0.305 \\
\hline \multicolumn{4}{|l|}{ SF-12 } \\
\hline preop. PCS & 0.10 & $-0.06 ; 0.26$ & 0.205 \\
\hline preop. MCS & 0.10 & $-0.01 ; 0.22$ & 0.080 \\
\hline
\end{tabular}

Table 1: Preoperative predictors of WOMAC pain change score.

The preoperative WOMAC pain score was the strongest determinant of the WOMAC pain change score in one year $(\mathrm{p}<0.001)$. The preoperative WOMAC function $(\mathrm{p}<0.001)$ and SF-12 mental health scores $(p=0.034)$ were the strongest determinants of the WOMAC function change score in one year after TKA.

\section{Discussion}

Our study shows that preoperative knee pain, function and mental function predicts TKA outcome. We found that lower preoperative WOMAC scores and better mental function according to SF-12 are strong determinants of greater pain and function score change at one year after surgery. Several studies have reported that more preoperative pain and anxiety predicts worse postoperative pain [1518]. Lingard A et al., concludes that patients with scores in the lowest WOMAC quartile group had the greatest improvement in their scores compared with the other groups [19]. A W-Dahl et al., reported that less pre-operative pain is a risk factor for no pain relief one year after surgery. Found that in addition to preoperative knee pain and pain at other sites, catastrophizing and mental health were the strongest independent predictors of persistent pain after TKA [20].

While many studies have explored how depression and lower mental health scores negatively impact TKA outcomes, the inverse has been seldom studied. Very few studies have looked in to the 
Citation: Sveikata T, Kanopa P, Daunaraite K, Mankevicius P, Tutkus V, et al. (2021) Influence of Preoperative Patient Factors on TKA Outcomes. J Gerontol Geriatr Med 7: 087.

effects TKA has on the patient's mental health [21]. The relationship of mental health, arthritis, and TKA is complex and not fully understood. Our findings show that following TKA, mental health status dramatically improves in patients with low MCS [22].

\begin{tabular}{|c|c|c|c|}
\hline \multicolumn{4}{|c|}{ Change WOMAC function } \\
\hline & Coef & $95 \%$ CI & p-value \\
\hline Age & -0.13 & $-0.29 ; 0.03$ & 0.113 \\
\hline \multicolumn{4}{|l|}{ Sex } \\
\hline Male & \multicolumn{3}{|l|}{ Ref. } \\
\hline Female & -2.35 & $-5.70 ; 0.99$ & 0.167 \\
\hline BMI & -0.05 & $-0.26 ; 0.16$ & 0.652 \\
\hline \multicolumn{4}{|l|}{ Social Support } \\
\hline No & \multicolumn{3}{|l|}{ Ref. } \\
\hline Yes & 1.74 & $-0.95 ; 4.42$ & 0.204 \\
\hline \multicolumn{4}{|l|}{ Level of Education } \\
\hline Higher & \multicolumn{3}{|l|}{ Ref. } \\
\hline Lower & -0.62 & $-3.24 ; 2.00$ & 0.642 \\
\hline \multicolumn{4}{|l|}{ Residence } \\
\hline Urban & \multicolumn{3}{|l|}{ Ref. } \\
\hline Rural & 1.28 & $-1.93 ; 4.49$ & 0.433 \\
\hline preop. WOMAC funct. & -0.93 & $-1.01 ;-0.85$ & $<0.001$ \\
\hline \multicolumn{4}{|l|}{ Charnley Class } \\
\hline $\mathbf{A}$ & \multicolumn{3}{|l|}{ Ref. } \\
\hline B & -1.95 & $-4.92 ; 1.03$ & 0.198 \\
\hline C & -1.83 & $-5.94 ; 2.28$ & 0.382 \\
\hline \multicolumn{4}{|l|}{ AHLBACK } \\
\hline $1+2$ & \multicolumn{3}{|l|}{ Ref. } \\
\hline $3+4$ & 0.62 & $-1.81 ; 3.05$ & 0.614 \\
\hline \multicolumn{4}{|l|}{ SF-12 } \\
\hline preop. PCS & 0.09 & $-0.08 ; 0.26$ & 0.302 \\
\hline preop. MCS & 0.14 & $-0.01 ; 0.26$ & 0.034 \\
\hline
\end{tabular}

Table 2: Preoperative predictors of WOMAC function change score.

According to the results of our study, the quality of life of people after TKA significantly improves. This is due to pain factors that are closely related to mental health. These data correlates with our findings as there is more room for pain and function improvement as preoperative scores are lower. Study strengths are its prospective design, high rate of return to follow-up, all patients were operated in a single institution with the same postoperative and rehabilitation protocol.

\section{Conclusion}

The preoperative WOMAC pain score was the strongest determinant of the WOMAC pain change score one year after TKA. The preoperative WOMAC function and SF-12 mental health scores were the strongest determinants of the WOMAC function change score one year after TKA. Lower preoperative knee pain, function scores and better mental health function results in greater change. Further studies are needed to assess the complex relationship of mental health and TKA. Specifically, it would be beneficial to evaluate the specific drivers of low emotional health and whether it is the result of pain and dysfunction brought on by arthrosis, a lack of social support, catastrophizing patient characteristics, or something else. Furthermore, it would be significant to study the impact of preoperative mental and emotional interventions on patients with low mental health to see whether mental health recovers and improvement also corresponds to recovered outcomes after TKA [21].

\section{Declaration of Conflicting Interests}

The author(s) declared no potential conflicts of interest with respect to the research, authorship, and/or publication of this article.

\section{References}

1. WHO Scientific Group on the Burden of Musculoskeletal Conditions at the Start of the New Millennium (2003) The burden of musculoskeletal conditions at the start of the new millennium. World Health Organ Tech Rep Ser 919.

2. Lau RL, Perruccio AV, Gandhi R, Mahomed NN (2012) The role of surgeon volume on patient outcome in total knee arthroplasty: A systematic review of the literature. BMC Musculoskelet Disord 13: 250.

3. Ethgen O, Bruyère O, Richy F, Dardennes C, Reginster JY (2004) Health-related quality of life in total hip and total knee arthroplasty. A qualitative and systematic review of the literature. J Bone Joint Surg Am 86: $963-974$

4. Robertsson O, Dunbar M, Pehrsson T, Knutson K, Lidgren L (2000) Patient satisfaction after knee arthroplasty: a report on 27,372 knees operated on between 1981 and 1995 in Sweden. Acta Orthop Scand 71: 262-267.

5. Giesinger JM, Hamilton DF, Jost B, Behrend H, Giesinger K (2015) WOMAC, EQ-5D and Knee Society Score Thresholds for Treatment Success After Total Knee Arthroplasty. J Arthroplasty 30: 2154-2158.

6. American College of Rheumatology (2011) Clinical Research Resources. American College of Rheumatology, Atlanta, USA.

7. Ali A, Sundberg M, Robertsson O, Dahlberg LE, Thorstensson CA, et al. (2014) Dissatisfied patients after total knee arthroplasty. Acta Orthop 85: 229-233.

8. Nuñez M, Lozano L, Nuñez E, Segur JM, Sastre S (2011) Factors influencing health-related quality of life after TKA in patients who are obese. Clin Orthop Relat Res 469: 1148-1153.

9. Barrack RL, Ruh EL, Chen J, Lombardi AV Jr, Berend KR, et al. (2014) Impact of socioeconomic factors on outcome of total knee arthroplasty. Clin Orthop Relat Res 472: 86-97.

10. Little W (2016) Phases of Aging: The Young-Old, Middle-Old, and OldOld. In: Little W (ed.). Introduction to Sociology.

11. WHO (2016) Global Database on Body Mass Index. WHO, Geneva, Switzerland.

12. Ahlbäck S (1968) Osteoarthrosis of the knee. A radiographic investigation. Acta Radiol Diagn (Stockh) 277: 7-72.

13. Charnley J, Halley DK (1975) Rate of wear in total hip replacement. Clin Orthop Relat Res: 170-179.

14. Ware J Jr, Kosinski M, Keller SD (1996) A 12-Item Short-Form Health Survey: construction of scales and preliminary tests of reliability and validity. Med Care 34: 220-233.

15. Brander VA, Stulberg SD, Adams AD, Harden RN, Bruehl S, et al. (2003) Predicting total knee replacement pain: A prospective, observational study. Clin Orthop Relat Res: 27-36.

16. Lingard EA, Riddle DL (2007) Impact of psychological distress on pain and function following knee arthroplasty. J Bone Joint Surg Am 89: 11611169. 
Citation: Sveikata T, Kanopa P, Daunaraite K, Mankevicius P, Tutkus V, et al. (2021) Influence of Preoperative Patient Factors on TKA Outcomes. J Gerontol Geriatr Med 7: 087.

17. Judge A, Arden NK, Cooper C, Kassim Javaid M, et al. (2012) Predictors of outcomes of total knee replacement surgery. Rheumatology (Oxford) 51: 1804-1813.

18. Escobar A, Quintana JM, Bilbao A, Azkárate J, Güenaga JI, et al. (2007) Effect of patient characteristics on reported outcomes after total knee replacement. Rheumatology (Oxford) 46: 112-119.

19. Lingard EA, Katz JN, Wright EA, Sledge CB, Kinemax Outcomes Group (2004) Predicting the outcome of total knee arthroplasty. J Bone Joint Surg Am 86: 2179-2186.
20. Robertsson O, Ranstam J, Sundberg M, W-Dahl A, Lidgren L (2014) The Swedish Knee Arthroplasty Register: A review. Bone Jt Res 3: 217-222.

21. Horst PK, Barrett AA, Huddleston JI 3rd, Maloney WJ, Goodman SB, et al. (2020) Total Knee Arthroplasty Has A Positive Effect on Patients With Low Mental Health Scores. J Arthroplasty 35: 112-115.

22. Nicassio PM (2010) Arthritis and psychiatric disorders: disentangling the relationship. J J Psychosom Res 68: 183-185. 


\section{Hif}

Advances In Industrial Biotechnology | ISSN: 2639-5665

Advances In Microbiology Research | ISSN: 2689-694X

Archives Of Surgery And Surgical Education | ISSN: 2689-3126

Archives Of Urology

Archives Of Zoological Studies | ISSN: 2640-7779

Current Trends Medical And Biological Engineering

International Journal Of Case Reports And Therapeutic Studies | ISSN: 2689-310X

Journal Of Addiction \& Addictive Disorders | ISSN: 2578-7276

Journal Of Agronomy \& Agricultural Science | ISSN: 2689-8292

Journal Of AIDS Clinical Research \& STDs | ISSN: 2572-7370

Journal Of Alcoholism Drug Abuse \& Substance Dependence | ISSN: 2572-9594

Journal Of Allergy Disorders \& Therapy | ISSN: 2470-749X

Journal Of Alternative Complementary \& Integrative Medicine | ISSN: 2470-7562

Journal Of Alzheimers \& Neurodegenerative Diseases | ISSN: 2572-9608

Journal Of Anesthesia \& Clinical Care | ISSN: 2378-8879

Journal Of Angiology \& Vascular Surgery | ISSN: 2572-7397

Journal Of Animal Research \& Veterinary Science | ISSN: 2639-375

Journal Of Aquaculture \& Fisheries | ISSN: 2576-5523

Journal Of Atmospheric \& Earth Sciences | ISSN: 2689-8780

Journal Of Biotech Research \& Biochemistry

Journal Of Brain \& Neuroscience Research

Journal Of Cancer Biology \& Treatment | ISSN: 2470-7546

Journal Of Cardiology Study \& Research | ISSN: 2640-768X

Journal Of Cell Biology \& Cell Metabolism | ISSN: 2381-1943

Journal Of Clinical Dermatology \& Therapy | ISSN: 2378-8771

Journal Of Clinical Immunology \& Immunotherapy | ISSN: 2378-8844

Journal Of Clinical Studies \& Medical Case Reports | ISSN: 2378-880

Journal Of Community Medicine \& Public Health Care | ISSN: 2381-1978

Journal Of Cytology \& Tissue Biology | ISSN: 2378-9107

Journal Of Dairy Research \& Technology | ISSN: 2688-9315

Journal Of Dentistry Oral Health \& Cosmesis | ISSN: 2473-6783

Journal Of Diabetes \& Metabolic Disorders | ISSN: 2381-201X

Journal Of Emergency Medicine Trauma \& Surgical Care | ISSN: 2378-8798

Journal Of Environmental Science Current Research | ISSN: 2643-5020

Journal Of Food Science \& Nutrition | ISSN: 2470-1076

Journal Of Forensic Legal \& Investigative Sciences | ISSN: 2473-733X

Journal Of Gastroenterology \& Hepatology Research | ISSN: 2574-2566
Journal Of Genetics \& Genomic Sciences | ISSN: 2574-2485

Journal Of Gerontology \& Geriatric Medicine | ISSN: 2381-8662

Journal Of Hematology Blood Transfusion \& Disorders | ISSN: 2572-2999

Journal Of Hospice \& Palliative Medical Care

Journal Of Human Endocrinology | ISSN: 2572-9640

Journal Of Infectious \& Non Infectious Diseases | ISSN: 2381-8654

Journal Of Internal Medicine \& Primary Healthcare | ISSN: 2574-2493

Journal Of Light \& Laser Current Trends

Journal Of Medicine Study \& Research | ISSN: 2639-5657

Journal Of Modern Chemical Sciences

Journal Of Nanotechnology Nanomedicine \& Nanobiotechnology | ISSN: 2381-2044

Journal Of Neonatology \& Clinical Pediatrics | ISSN: 2378-878X

Journal Of Nephrology \& Renal Therapy | ISSN: 2473-7313

Journal Of Non Invasive Vascular Investigation | ISSN: 2572-7400

Journal Of Nuclear Medicine Radiology \& Radiation Therapy | ISSN: 2572-7419

Journal Of Obesity \& Weight Loss | ISSN: 2473-7372

Journal Of Ophthalmology \& Clinical Research | ISSN: 2378-8887

Journal Of Orthopedic Research \& Physiotherapy | ISSN: 2381-2052

Journal Of Otolaryngology Head \& Neck Surgery | ISSN: 2573-010X

Journal Of Pathology Clinical \& Medical Research

Journal Of Pharmacology Pharmaceutics \& Pharmacovigilance | ISSN: 2639-5649

Journal Of Physical Medicine Rehabilitation \& Disabilities | ISSN: 2381-8670

Journal Of Plant Science Current Research | ISSN: 2639-3743

Journal Of Practical \& Professional Nursing | ISSN: 2639-568

Journal Of Protein Research \& Bioinformatics

Journal Of Psychiatry Depression \& Anxiety | ISSN: 2573-0150

Journal Of Pulmonary Medicine \& Respiratory Research | ISSN: 2573-0177

Journal Of Reproductive Medicine Gynaecology \& Obstetrics | ISSN: 2574-2574

Journal Of Stem Cells Research Development \& Therapy | ISSN: 2381-2060

Journal Of Surgery Current Trends \& Innovations | ISSN: 2578-7284

Journal Of Toxicology Current Research | ISSN: 2639-3735

Journal Of Translational Science And Research

Journal Of Vaccines Research \& Vaccination | ISSN: 2573-0193

Journal Of Virology \& Antivirals

Sports Medicine And Injury Care Journal | ISSN: 2689-8829

Trends In Anatomy \& Physiology | ISSN: 2640-7752

Submit Your Manuscript: https://www.heraldopenaccess.us/submit-manuscript 